\title{
Ruptured intracranial aneurysm in a patient with autosomal recessive polycystic kidney disease
}

\author{
*Jennifer L. Perez, PhD,,1,2 Michael M. McDowell, MD,,2 Benjamin Zussman, MD,1 \\ Ashutosh P. Jadhav, MD, PhD, ${ }^{1,3}$ Yosuke Miyashita, MD, ${ }^{4}$ Patrick McKiernan, MD, ${ }^{5}$ and \\ Stephanie Greene, MD ${ }^{1,2}$
}

\begin{abstract}
Departments of ${ }^{1}$ Neurological Surgery and ${ }^{3}$ Neurology, University of Pittsburgh Medical Center; and Divisions of ${ }^{2}$ Pediatric Neurological Surgery, ${ }^{4}$ Pediatric Nephrology, and ${ }^{5}$ Pediatric Hepatology, Children's Hospital of Pittsburgh, Pennsylvania

Aneurysmal rupture can result in devastating neurological consequences and can be complicated by comorbid disease processes. Patients with autosomal recessive polycystic kidney disease (ARPKD) have a low rate of reported aneurysms, but this may be due to the relative high rate of end-stage illnesses early in childhood. Authors here report the case of a 10-year-old boy with ARPKD who presented with a Hunt and Hess grade $V$ subarachnoid hemorrhage requiring emergency ventriculostomy, embolization, and decompressive craniectomy. Despite initial improvements in his neurological status, the patient succumbed to hepatic failure. Given the catastrophic outcomes of subarachnoid hemorrhage in young patients, early radiographic screening in those with ARPKD may be warranted.

https://thejns.org/doi/abs/10.3171/2018.8.PEDS18286
\end{abstract}

KEYWORDS intracranial aneurysm; ruptured aneurysm; polycystic kidney disease; ARPKD; vascular disorders

$\mathrm{A}$ UTOSOMAL recessive polycystic kidney disease (ARPKD) is a rare congenital fibrocystic disease of the kidneys and liver defined by a mutation in the gene PKHDl, which encodes fibrocystin..$^{16}$ The incidence of ARPKD is approximately 1 case in 20,000 live births. The disease is most commonly diagnosed in newborns with a prenatal history of oligohydramnios and enlarged echogenic kidneys with fusiform dilation of the collecting ducts. ${ }^{10}$ Liver disease characterized by congenital hepatic fibrosis and Caroli syndrome (a combination of ARPKD, congenital hepatic fibrosis, portal hypertension, and intrahepatic bile duct dilation) occurs in at least $50 \%$ of cases. ${ }^{6,7}$ Cerebral aneurysms occur in 5\%-10\% of patients with autosomal dominant polycystic kidney disease (ADPKD) ${ }_{19}$ but little has been published about intracranial aneurysms in ARPKD. Here we present the fifth and youngest reported case (to our knowledge) of an intracranial aneurysm in a patient with ARPKD and the first mortality from a ruptured intracranial aneurysm in a patient with ARPKD.

\section{Case Report}

History and Examination

Twelve hours after the onset of the worst headache of his life, a 10-year-old boy presented to Children's Hospital of Pittsburgh with progressive obtundation. He had a history of ARPKD due to a compound heterozygote mutation in $P K H D 1$, congenital hepatic fibrosis, portal hypertension with grade 2 esophageal varices, systemic hypertension, and autism. In transit he had been intubated for unresponsiveness, and he was subsequently found to have a Hunt and Hess grade $\mathrm{V}$ subarachnoid hemorrhage with a Fisher grade 4 (subarachnoid, intraparenchymal, and intraventricular) hemorrhage on initial imaging (Fig. 1). Upon his ar-

ABBREVIATIONS ADPKD = autosomal dominant polycystic kidney disease; $A R P K D=$ autosomal recessive polycystic kidney disease; EEG = electroencephalography; $E V D=$ external ventricular drain; $M R A=M R$ angiography; $P O D=$ postoperative day.

SUBMITTED May 15, 2018. ACCEPTED August 1, 2018

INCLUDE WHEN CITING Published online October 12, 2019; DOI: 10.3171/2018.8.PEDS18286.

* J.L.P. and M.M.M. contributed equally to this paper. 


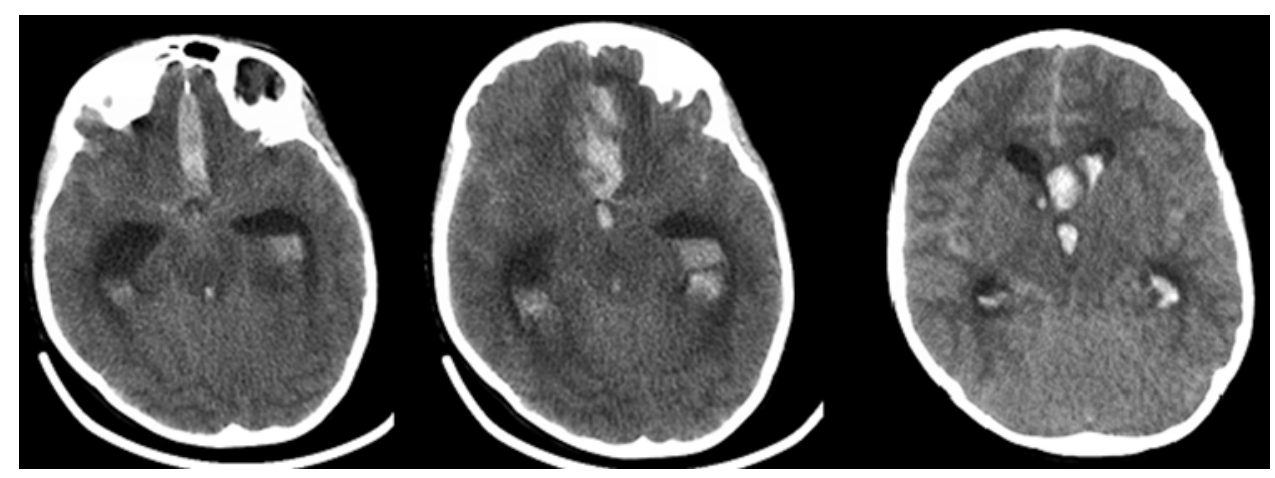

FIG. 1. Axial head CT scans demonstrating diffuse intraventricular hemorrhage, subarachnoid hemorrhage, and bilateral gyrus rectus hemorrhage with ventriculomegaly.

rival, examination revealed pupils that were equal, round, and reactive to light, and he had a single positive corneal reflex but no cough or gag reflex. No motor response was elicited through the application of painful stimuli, though the absence of paralytic medications was confirmed with a peripheral nerve stimulator.

\section{Treatment}

A right frontal external ventricular drain (EVD) was emergently placed, and the patient was taken to the angiography suite. Digital subtraction angiography revealed an aneurysm at the junction of the left anterior communicating artery (Fig. 2), which was coiled. The patient developed transient hypertension and bradycardia just prior to the initiation of coiling, both of which spontaneously resolved. A postprocedural head CT scan demonstrated evidence of a pretreatment rehemorrhage consisting of diffuse subarachnoid hemorrhage and complete casting of the ventricular system, as well as signs of intracranial hypertension and imminent herniation (Fig. 3). It was unclear if this was spontaneous or the result of changes in pressure gradients caused by ventriculostomy placement or angiography. After a discussion with the family, we took the patient to the operating room for an emergency Kjellberg (bilateral frontotemporal) decompressive craniectomy and bilateral large-bore EVD placement. Given the rapid onset of symptoms, previous level of function, and severe clot burden, this measure was felt to be the best option for the patient's possible stabilization despite the controversy that currently exists in the literature regarding decompression for diffuse brain injury in children..$^{1,18}$ When the dura mater was opened, the brain began to immediately protrude from the skull, and copious subarachnoid hemorrhage was visible. The skin was closed in a watertight fashion after hemostasis was achieved.

\section{Posttreatment Course}

He was placed on judicious euvolemia to mild hypervolemia and mild pressure support due to low arterial pressures to prevent vasospasm. The severe intraventricular clot burden and the need for frequent flushing of the EVDs due to clotting were felt to represent a high-risk situation warranting judicious use of thrombolytic therapy, whose risks and benefits were discussed with the family. Intraventricular tissue plasminogen activator was injected in an alternating fashion between the two EVDs starting on postoperative day (POD) 1 ( $0.5 \mathrm{mg}$ every 8 hours for 4 days) in an attempt to normalize his ventricular size and improve his neurological exam. After completion of the injection protocol, there was a substantial radiographic reduction in the intraventricular hematoma burden. Transcranial Doppler ultrasonography studies were initiated
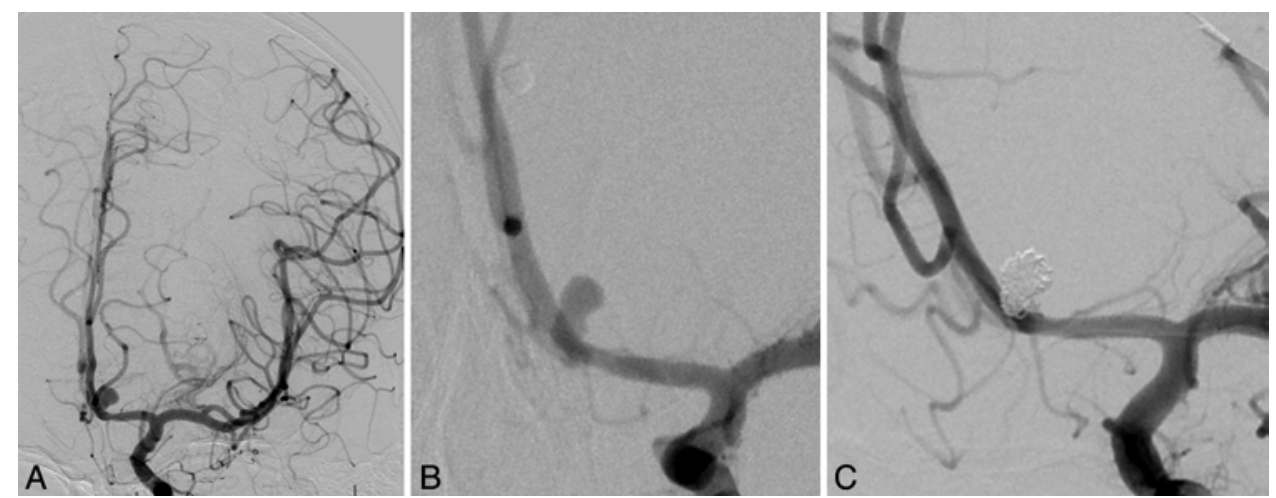

FIG. 2. Left internal carotid artery injection angiograms demonstrate an $8 \times 4-\mathrm{mm}$ irregular aneurysm at the junction of the left anterior communicating artery with the $A_{1}$ and $A_{2}$ segments: anteroposterior $(A)$, oblique precoiling $(B)$, and oblique postcoiling $(C)$ views. 


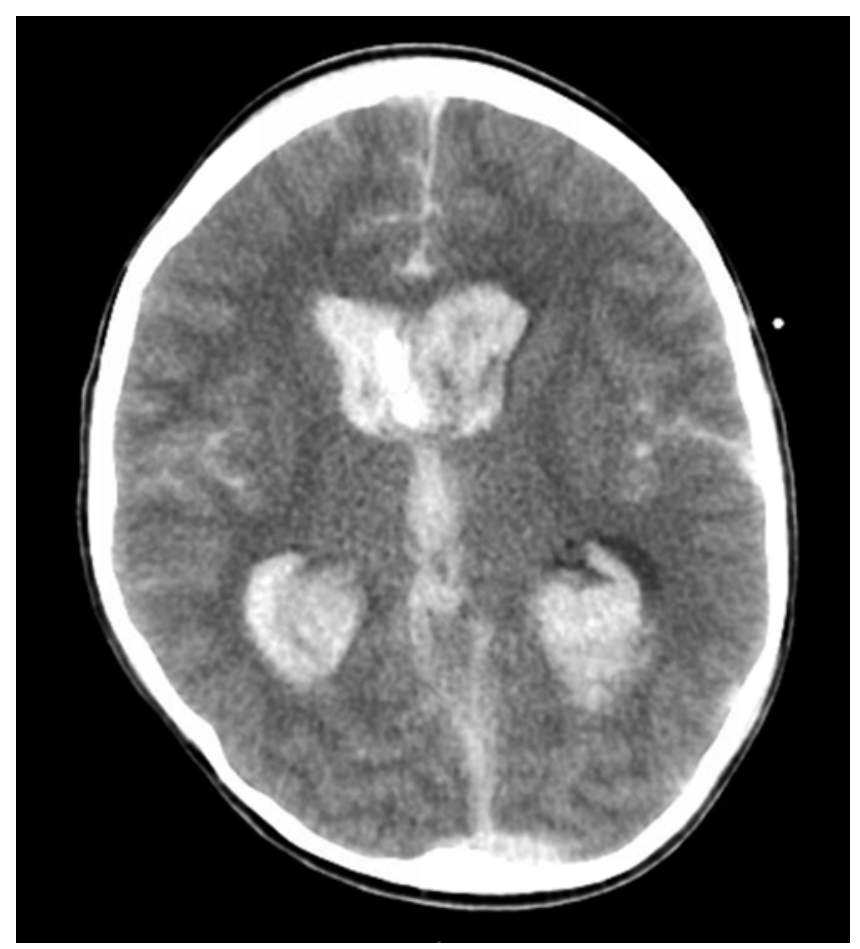

FIG. 3. Postprocedural head CT demonstrating worsened intraventricular hemorrhage and ventriculomegaly.

on POD 3. They remained stable until POD 11, when the computed Lindegaard ratio became elevated on two sets of transcranial Doppler studies. Angiography was repeated, and the absence of vasospasm was demonstrated.

The patient was extubated on POD 7 after an angiogram demonstrated continued successful aneurysm obliteration. He was opening his eyes spontaneously and moving purposefully with all extremities, but he developed acute respiratory distress and was reintubated that evening. He was found to be in nonconvulsive status epilepticus on electroencephalography (EEG), which was controlled with levetiracetam and phenobarbital. On POD 8 he developed fever, fluid overload, and hypotension with worsening renal function with a serum creatinine of 2.24 $\mathrm{mg} / \mathrm{dl}$ (baseline $1.0 \mathrm{mg} / \mathrm{dl}$ ). From PODs 9 to 12, he also developed progressive liver dysfunction resulting in liver failure and coagulopathy, with presumed severe encephalopathy evidenced by persistent cerebral edema as well as diffuse cortical dysfunction on EEG. The patient was initially supported with lactulose and vitamin K supplementation. On POD 13, he was started on a plasmapheresis protocol and continuous renal replacement therapy, as well as lactulose for hyperammonemia given that he had developed an acute hepatorenal syndrome with persistent coagulopathy. An abdominal ultrasound was concerning for right hepatic lobe infarction and dilated hepatic veins with flow reversal but a patent hepatic artery. After 5 days of plasma exchange and continuous renal replacement therapy, he did not demonstrate any meaningful improvement in liver function. Following a multidisciplinary review, he was judged to be unfit for liver transplantation. After extensive counseling, the family elected to remove life-sustaining therapy, and the patient died on POD 23.

\section{Discussion}

Here we present the fifth case of an intracranial aneurysm in a patient with ARPKD. This patient is the youngest of the cohort to have suffered aneurysm rupture and the first to die of exacerbated complications of his condition. To our knowledge, there have been only four previously reported cases of intracranial aneurysms in patients with ARPKD (Table 1). ${ }^{3,4,11}$ Prior to our report, the youngest patient was a 12-year-old boy with ARPKD and congenital hepatic failure who had presented with intracranial subarachnoid hemorrhage from a ruptured basilar tip aneurysm and an unruptured left middle cerebral artery aneurysm. This patient had a good clinical outcome following endovascular coiling. ${ }^{4}$

Only $0.5 \%$ to $4.6 \%$ of all aneurysms occur in patients 18 years of age and younger, thus making it an uncommon disease at most pediatric centers. ${ }^{8,15}$ The incidence of three cases with multiple aneurysms in patients with ARPKD among the five reported cases is a greater frequency than

TABLE 1. Summary of existing reported cases of intracranial aneurysms in patients with ARPKD

\begin{tabular}{|c|c|c|c|c|c|c|}
\hline $\begin{array}{l}\text { Authors } \\
\& \text { Year }\end{array}$ & $\begin{array}{l}\text { Age (yrs) } \\
\text { Sex }\end{array}$ & Aneurysm Type & Presentation & Intervention & Outcome & FU \\
\hline $\begin{array}{l}\text { De Blasi et } \\
\quad \text { al., } 1997\end{array}$ & $12, \mathrm{M}$ & $\begin{array}{l}\text { Basilar tip, It } \\
\text { MCA }\end{array}$ & $\begin{array}{l}\text { Presented w/ headaches, nausea, vomiting, } \\
\qquad \& \mathrm{HH} \text { grade II SAH }\end{array}$ & $\begin{array}{l}\text { Endovascular coiling of basilar } \\
\text { artery, clipping of It MCA }\end{array}$ & $\begin{array}{l}\text { Complete } \\
\text { recovery }\end{array}$ & $3 \mathrm{yrs}$ \\
\hline $\begin{array}{l}\text { Neumann et } \\
\text { al., } 1999\end{array}$ & $31, F$ & $\begin{array}{l}\text { ACoA, rt MCA, It } \\
\text { PCoA, It AChA }\end{array}$ & Routine screening for reported headaches & 2-stage clipping & Asymptomatic & $3 \mathrm{mos}$ \\
\hline $\begin{array}{l}\text { Lilova \& } \\
\quad \text { Petkov, } \\
2001\end{array}$ & $2.5, F$ & MCA \& PCA & $\begin{array}{l}\text { An episode of vomiting, dizziness, \& lethargy } \\
\text { w/o accompanying hypertension prompted } \\
\text { MRA of brain; patient was growing well } \\
\text { \& neurologically asymptomatic at age } 4 \text { yrs }\end{array}$ & Observation & Asymptomatic & $1.5 \mathrm{yrs}$ \\
\hline $\begin{array}{l}\text { Chalhoub et } \\
\text { al., } 2013\end{array}$ & $21, \mathrm{M}$ & Rt AChA & $\begin{array}{l}\text { Presented w/ sudden onset of intense oc- } \\
\text { cipital headache w/ photophobia, nausea, } \\
\text { vomiting, \& rt parietal hematoma }\end{array}$ & Clipping & $\begin{array}{l}\text { Complete } \\
\text { recovery }\end{array}$ & 12 days \\
\hline
\end{tabular}

$\mathrm{AChA}=$ anterior choroidal artery; $\mathrm{ACoA}=$ anterior communicating artery; $\mathrm{FU}=$ follow-up; $\mathrm{HH}=$ Hunt and Hess; $\mathrm{MCA}=$ middle cerebral artery; $\mathrm{PCA}=$ posterior cerebral artery; $\mathrm{PCOA}=$ posterior communicating artery; $\mathrm{SAH}$ = subarachnoid hemorrhage. 
anticipated by chance and is suggestive of a possible relationship between ARPKD and intracranial aneurysms. ${ }^{12,13}$ In contrast, intracranial aneurysms are well-established complications of ADPKD and are reported to occur in $5 \%-10 \%$ of patients. ${ }^{8}$ The rate of aneurysm rupture during childhood in ADPKD is approximately $10 \%$. Assuming a similar rupture risk in ARPKD, the three documented cases of aneurysm rupture in the ARPKD patients may represent a similar fraction of a larger, undetected group of ARPKD patients with asymptomatic intracranial aneurysms..$^{14}$ Whether screening MRI should be done in all ADPKD patients at designated times or whether MRI is only indicated in those at higher risk (personal or family history of intracranial aneurysm as well as those with neurological symptoms) remains a matter of controversy. Recently, an increasing number of studies have attempted to identify ADPKD populations at higher risk for intracranial aneurysms and the most cost-effective screening protocol. Yoshida et al. showed that the incidence of intracranial aneurysms was increased in patients who were older and female and had an enlarged kidney size. ${ }^{17}$ A cost-utility analysis by Flahault et al. revealed that systematic MR angiography (MRA) screening for all ADPKD patients, as compared to targeted screening, was cost-effective and provided an increase in quality life-years. ${ }^{5}$

The most obvious risk factor for intracranial aneurysm formation in patients with ADPKD is hypertension, a condition also frequently found in patients with ARPKD. If the risk factors are the same, it logically follows that the risk of aneurysm formation may be the same. While intracranial aneurysms have been thought to be sporadic, unrelated occurrences in patients with ARPKD, the lack of an association could be explained by the absence of previously reported cases and the shortened life expectancy of these patients. However, as a greater number of patients live into adulthood through the medical management of comorbid conditions, the potential risk of an aneurysm and its rupture increases. If patients with ARPKD were systematically screened, the number of intracranial aneurysms diagnosed in this population may well be increased. With noninvasive screening techniques such as MRA, intracranial aneurysm diagnosis could be made sooner, allowing for earlier, elective treatment and more favorable outcomes. Subarachnoid hemorrhage following aneurysm rupture is associated with mortality rates approaching 50\% and severe neurological deficits in $50 \%$ of survivors, so avoiding aneurysm rupture prior to treatment is highly desirable. ${ }^{2}$ However, this potential benefit must be balanced with the risks of testing and intervention, the patient's clinical condition, and the risk tolerance of the family.

Aneurysm rupture often results in devastating neurological consequences and, as in our case, may be complicated by preexisting disease processes. Congenital hepatic fibrosis is usually characterized by normal liver function with isolated portal hypertension, and liver failure is unusual. Our case highlights the vulnerability of some patients with ARPKD, in whom stressors such as aneurysm rupture and its treatment may derange patients' tenuous physiological balance, leading to end-stage renal disease and irreversible acute liver failure. ${ }^{9}$

Patients with ARPKD have a low rate of reported intra- cranial aneurysms, but this may change as life expectancies increase with the improved medical management of comorbidities. Several reported cases have had multiple aneurysms, an unexpectedly high frequency. Given the potentially life-threatening complications of subarachnoid hemorrhage in young patients and the known association between ADPKD and aneurysms, further study into a possible association between ARPKD and aneurysms is warranted. To date, there are insufficient data to conclude whether early MRA screening is warranted in all patients with ARPKD.

\section{References}

1. Appelboom G, Zoller SD, Piazza MA, Szpalski C, Bruce SS, McDowell MM, et al: Traumatic brain injury in pediatric patients: evidence for the effectiveness of decompressive surgery. Neurosurg Focus 31(5):E5, 2011

2. Bederson JB, Connolly ES Jr, Batjer HH, Dacey RG, Dion JE, Diringer MN, et al: Guidelines for the management of aneurysmal subarachnoid hemorrhage: a statement for healthcare professionals from a special writing group of the Stroke Council, American Heart Association. Stroke 40:994-1025, 2009

3. Chalhoub V, Abi-Rafeh L, Hachem K, Ayoub E, Yazbeck P: Intracranial aneurysm and recessive polycystic kidney disease: the third reported case. JAMA Neurol 70:114-116, 2013

4. De Blasi R, Lasjaunias P, Rodesch G, Alvarez H: Endovascular treatment of a ruptured intracranial arterial aneurysm in a 12-year-old child with recessive polycystic kidney disease. Interv Neuroradiol 3:333-336, 1997

5. Flahault A, Trystram D, Nataf F, Fouchard M, Knebelmann $\mathrm{B}$, Grünfeld JP, et al: Screening for intracranial aneurysms in autosomal dominant polycystic kidney disease is costeffective. Kidney Int 93:716-726, 2018

6. Guay-Woodford LM, Desmond RA: Autosomal recessive polycystic kidney disease: the clinical experience in North America. Pediatrics 111:1072-1080, 2003

7. Harris PC, Torres VE: Polycystic kidney disease. Annu Rev Med 60:321-337, 2009

8. Jian BJ, Hetts SW, Lawton MT, Gupta N: Pediatric intracranial aneurysms. Neurosurg Clin N Am 21:491-501, 2010

9. Khan K, Schwarzenberg SJ, Sharp HL, Matas AJ, Chavers BM: Morbidity from congenital hepatic fibrosis after renal transplantation for autosomal recessive polycystic kidney disease. Am J Transplant 2:360-365, 2002

10. Liang JJ, Kamath PS: Caroli syndrome. Mayo Clin Proc 88:e59, 2013

11. Lilova MI, Petkov DL: Intracranial aneurysms in a child with autosomal recessive polycystic kidney disease. Pediatr Nephrol 16:1030-1032, 2001

12. McDowell MM, Zhao Y, Kellner CP, Barton SM, Sussman E, Claassen J, et al: Demographic and clinical predictors of multiple intracranial aneurysms in patients with subarachnoid hemorrhage. J Neurosurg 128:961-968, 2018

13. Neumann HP, Krumme B, van Velthoven V, Orszagh M, Zerres K: Multiple intracranial aneurysms in a patient with autosomal recessive polycystic kidney disease. Nephrol Dial Transplant 14:936-939, 1999

14. Pirson Y, Chauveau D, Torres V: Management of cerebral aneurysms in autosomal dominant polycystic kidney disease. J Am Soc Nephrol 13:269-276, 2002

15. Rinkel GJ, Djibuti M, Algra A, van Gijn J: Prevalence and risk of rupture of intracranial aneurysms: a systematic review. Stroke 29:251-256, 1998

16. Wehrman A, Kriegermeier A, Wen J: Diagnosis and manage- 
ment of hepatobiliary complications in autosomal recessive polycystic kidney disease. Front Pediatr 5:124, 2017

17. Yoshida H, Higashihara E, Maruyama K, Nutahara K, Nitatori T, Miyazaki I, et al: Relationship between intracranial aneurysms and the severity of autosomal dominant polycystic kidney disease. Acta Neurochir (Wien) 159:2325-2330, 2017

18. Young AMH, Kolias AG, Hutchinson PJ: Decompressive craniectomy for traumatic intracranial hypertension: application in children. Childs Nerv Syst 33:1745-1750, 2017

19. Zhou Z, Xu Y, Delcourt C, Shan J, Li Q, Xu J, et al: Is regular screening for intracranial aneurysm necessary in patients with autosomal dominant polycystic kidney disease? A systematic review and meta-analysis. Cerebrovasc Dis 44:75-82, 2017

\section{Disclosures}

The authors report no conflict of interest concerning the materials or methods used in this study or the findings specified in this paper.

\section{Author Contributions}

Conception and design: McDowell, Perez, Greene. Acquisition of data: McDowell, Perez. Analysis and interpretation of data: McDowell, Perez, Greene. Drafting the article: all authors. Critically revising the article: all authors. Reviewed submitted version of manuscript: all authors. Approved the final version of the manuscript on behalf of all authors: McDowell.

\section{Correspondence}

Michael M. McDowell: University of Pittsburgh Medical Center, Pittsburgh, PA. mcdowellmm2@upmc.edu. 